\title{
Fluctuations in coral reef fish densities after environmental disturbances on the northern Great Barrier Reef
}

\author{
Zegni Triki ${ }^{\text {Corresp.., }}{ }^{1}$, Redouan Bshary ${ }^{1}$ \\ ${ }^{1}$ Institute of Biology, University of Neuchâtel, Neuchâtel, NE, Switzerland \\ Corresponding Author: Zegni Triki \\ Email address: zegni.triki@unine.ch
}

Global warming is predicted to increase the frequency and or severity of many disturbances including cyclones, storms, and prolonged heatwaves. The coral reef at Lizard Island, part of the Great Barrier Reef, has been recently exposed to a sequence of severe tropical cyclones (i.e., Ita in 2014 and Nathan in 2015) and a coral bleaching in the year 2016. Reef fishes are an essential part of the coral reef ecosystem, and their abundance is thus a good marker to estimate the magnitude of such disturbances. Here, we examined whether the recent disturbances at Lizard Island had an impact on the coral reef fish communities. To do this, we examined fish survey data collected before and after the disturbances for potential changes in total fish density post-disturbance. Also, by sorting fish species into eleven functional groups based on their trophic level (i.e., diet), we further explored the density changes within each functional group. Our findings showed an overall decline of $68 \%$ in fish density post-disturbance, with a significant density decrease in nine of eleven trophic groups. These nine groups were: browsers, corallivores, detritivores, excavator/scrapers, grazers, macro-invertivores, pisci-invertivores, planktivores, and spongivores. The piscivores, on the other hand, were the only "winners", wherein their density showed an increase post-disturbance. These changes within functional groups might have a further impact on the trophodynamics of the food web. In summary, our findings provide evidence that the fish assemblage on the reefs around Lizard Island was considerably affected by extreme weather events, leading to changes in the functional composition of the reef fish assemblage. 
1

2

3

4 Authors: Zegni Triki* \& Redouan Bshary

5 Affiliations:

6 Institute of Biology, University of Neuchâtel, Emile-Argand 11, 2000 Neuchâtel, Switzerland

7 *Correspondence to Zegni Triki, zegni.triki@unine.ch

9

10

11

12

13 


\section{Abstract}

15

16 Global warming is predicted to increase the frequency and or severity of many disturbances

17 including cyclones, storms, and prolonged heatwaves. The coral reef at Lizard Island, part of the

18 Great Barrier Reef, has been recently exposed to a sequence of severe tropical cyclones (i.e., Ita

19 in 2014 and Nathan in 2015) and a coral bleaching in the year 2016. Reef fishes are an essential

20 part of the coral reef ecosystem, and their abundance is thus a good marker to estimate the

21 magnitude of such disturbances. Here, we examined whether the recent disturbances at Lizard

22 Island had an impact on the coral reef fish communities. To do this, we examined fish survey

23 data collected before and after the disturbances for potential changes in total fish density post-

24 disturbance. Also, by sorting fish species into eleven functional groups based on their trophic

25 level (i.e., diet), we further explored the density changes within each functional group. Our

26 findings showed an overall decline of $68 \%$ in fish density post-disturbance, with a significant

27 density decrease in nine of eleven trophic groups. These nine groups were: browsers,

28 corallivores, detritivores, excavator/scrapers, grazers, macro-invertivores, pisci-invertivores,

29 planktivores, and spongivores. The piscivores, on the other hand, were the only "winners",

30 wherein their density showed an increase post-disturbance. These changes within functional

31 groups might have a further impact on the trophodynamics of the food web. In summary, our

32 findings provide evidence that the fish assemblage on the reefs around Lizard Island was

33 considerably affected by extreme weather events, leading to changes in the functional 34 composition of the reef fish assemblage. 


\section{Introduction:}

39 The recently observed increase in frequency and magnitude of extreme weather events is 40 attributed to anthropogenic global warming (Cai et al., 2014; Cheal et al., 2017; Hughes et al.,

41 2018). Such extreme events are a great threat to coral reefs worldwide (Hughes et al., 2017).

42 Coral reefs are one of the world's most diverse ecosystems, with fish as an essential component.

43 Losing live corals can thus have severe impacts on the diversity and stability of this ecosystem

44 (Bellwood et al., 2006; Pratchett et al., 2008, 2011; Munday et al., 2008). For instance, one of the 45 threats of extreme weather events to coral reefs is the prolonged El Niño cycles and the resulting 46 coral bleaching. El Niño is a naturally occurring climatic event that brings warm water towards 47 the Indo-Pacific. A recent prolonged El Niño event led to an increase in seawater temperatures 48 (Cai et al., 2014; Hoegh-Guldberg \& Ridgway, 2016). In these conditions, overstressed coral 49 tissues expel their intracellular symbionts "zooxanthella" (i.e., symbionts from which corals gain 50 their different pigmentations) which causes bleaching. The resulting bleached corals may die if 51 they do not re-establish the symbiotic relationship with the zooxanthella within a range of six 52 months post-bleaching (DiazPulido \& McCook, 2002). In addition to the threat of coral 53 bleaching, cyclones can also be destructive due to the formation of strong waves that can damage 54 exposed coral reef fields (Cheal et al., 2017). Both cyclones and coral bleaching can thus result 55 in environmental degradation and habitat loss (Pizarro et al., 2017; Hughes et al., 2017).

57 Using fish assemblages, diversity, and abundance, researchers can evaluate the biological 58 integrity and quality of a given habitat (Karr, 1981; Ganasan \& Hughes, 1998). Several studies, 59 for instance, showed that fish abundance could be negatively affected by environmental 
60 disturbances due to climate change, either directly through abiotic factors such as temperature

61 and ocean acidification (Ferrari et al., 2011; Browman, 2016), or indirectly through habitat loss

62 (Munday et al., 2008). Thus, changes in fish abundance should provide reliable information on

63 habitat quality.

64

65 Habitat degradation is known to have a negative impact on overall fish density (Munday, 2004;

66 Wilson et al., 2008b, 2010). Bellwood et al. (2004) argue that further insights can be gained

67 from analysing fish functional groups but only in addition to knowing the cause and extent of the

68 habitat degradation. Therefore, exploring potential changes at the level of fish groups that share

69 the same function (i.e., functional group) might yield additional information about the

70 mechanism and effect of the impact. For instance, three main functional groups displaying

71 herbivore dietary traits (i.e., corallivores, excavator/scrapers, and grazers) can play an important

72 role in coral reef recovery. The functional role of these three herbivores is complementary, and

73 together their presence on the reef can play a role in its resistance to disturbances (Bellwood et

74 al., 2004). In addition to the densities of herbivorous fishes, other factors also play a major role

75 in coral reef resistance and recovery, such as the complexity of coral structure and water depth

76 (Graham et al., 2015).

77

78 A suitable location to explore potential changes in fish abundance and functional groups after 79 environmental disturbances is Lizard Island (Pizarro et al., 2017; Emslie, Cheal \& Logan, 2017;

80 Triki et al., 2018). The island is located in the northern Great Barrier Reef (GBR), Australia,

81 within a marine reserve. The island was impacted by a sequence of extreme weather events three

82 years in a row: In April 2014, Cyclone Ita hit Lizard Island (Pizarro et al., 2017), reaching an 
83 intensity of category 5 on the Australian scale (Puotinen et al., 2016). In April 2015, the island

84 was again exposed to another severe cyclone, Cyclone Nathan, a severe category 4 cyclone

85 (Pizarro et al., 2017). And finally, in February/March of 2016, the GBR was affected by a 86 massive coral bleaching event, resulting in more than $60 \%$ bleached coral cover (Hughes et al., 87 2017).

88 In this study, we asked in to what extent fish communities would change as a function of 89 environmental disturbances at Lizard Island. To do so, we compared fish densities before and 90 after disturbances both overall and by functional group. We expected to find a decline in fish 91 species that rely directly or indirectly on live corals for their diet (Wilson et al., 2006). In 92 contrast, due to the colonisation of dead corals by microalgae (Cheal et al., 2010) we expected an 93 increase in the abundance of various herbivorous fish species specialised on such algae (Randall, 94 1961).

95

96 Methods:

$97 \quad$ Field site and fish census:

98 The study was conducted on the reef around Lizard Island, Great Barrier Reef, Australia $99\left(14.6682^{\circ} \mathrm{S}, 145.4604^{\circ} \mathrm{E}\right)$. The study was carried out at two locations: Mermaid Cove and 100 Northern Horseshoe reefs. Mermaid Cove forms a continuous fringing reef of approximatively 101 35,000 m² (i.e., estimated from maps: https://www.freemaptools.com/area-calculator.htm), with 102 a depth range from 1 to $7 \mathrm{~m}$. The reef is located in a small bay on the northern side of Lizard 103 Island. The other location, Northern Horseshoe reef, is also a continuous reef consisting of a 104 coral garden of approximately $17,000 \mathrm{~m}^{2}$, with a depth range from 1 to $4 \mathrm{~m}$. The reef is located 105 on the western side of the island (see Figure 1). After the 2014 and 2015 cyclones, the reef at 
106 Mermaid Cove was heavily damaged. Northern Horseshoe reef, however, had been protected

107 from these two cyclones due to its location within the lagoon (Pizarro et al., 2017; Lizard Island

108 Research Station directors, personal communication). The coral bleaching event in 2016 affected

109 all the reefs around Lizard Island including our two study sites.

110

111 We used underwater visual fish census methods based on earlier studies by Wismer et al. (2014)

112 and Triki et al. (2018). Within each location, the observer swam ten replicates of a $30 \mathrm{~m}$ transect

113 line on the reef flat. Due to the different shape of the reef at the two locations, the transect line

114 was placed parallel to the reef crest at Mermaid Cove, whereas at Northern Horseshoe it was

115 placed parallel to the shoreline (Following methods in Wismer et al., 2014). Along the $30 \mathrm{~m}$

116 transect line the observer first recorded the number of all large visible fish (i.e., species with

117 body total length TL $>10 \mathrm{~cm}$ ) on a $5 \mathrm{~m}$ wide area, then the number of small visible fish (i.e.,

118 species with body TL $\leq 10 \mathrm{~cm}$ ) on a $1 \mathrm{~m}$ wide area. Each of the ten transect replicates, within

119 each location, were sampled at least 10 meters apart from each other to minimise possible

120 resampling of the same individuals. Only adult fish were surveyed, and their species was

121 identified. Overall, there were 163 species identified in our survey (Table S1). All fish counts

122 (i.e., large and small fish) were scaled per $150 \mathrm{~m}^{2}$ to facilitate further statistical analyses.

123

124 The fish surveys from the two study locations were collected at the same time of day in a similar 125 way between June and August within each year of data collection. Data were collected at 126 Mermaid Cove in 2011 (in Wismer et al., 2014), 2016 (in Triki et al., 2018), and 2017. At

127 Northern Horseshoe, the fish census was conducted in 2014, 2016 (in Triki et al., 2018) and 128 2017. We labelled the data collected in 2011 (i.e., from Mermaid Cove) and 2014 (i.e., from 
129 Northern Horseshoe), as fish survey before disturbances. Subsequently, the fish surveys in 2016 130 and 2017 were labelled as data after the disturbances (as in Triki et al., 2018).

131

132 Fish species were then categorised into functional groups based on the species' trophic level 133 (Butterfield \& Suding, 2013; Brandl et al., 2016). We sorted fish species into 11 trophic-

134 functional groups (Table 1). The categorisation into dietary functional groups followed methods 135 in studies by Wernberg et al. (2013) and MacNeil et al. (2015) (see Table S1 in the 136 Supplementary material). For the few species for which trophic level was missing from these 137 studies, we completed information from the FishBase (Froese \& Pauly, 2016).

139 Statistical analyses:

140

141 All data analyses and figures were generated by using the Software R version 3.5.1. All the 142 recorded fish species were included in the present analyses. Fish counts on each transect 143 represented fish abundance. Therefore, the transect line was the statistical unit in our sample 144 size. Overall, we ran two statistical models. We fit the first model to test for the overall change in 145 total fish abundance before and after the disturbances. It was a General Linear Model (GLM), 146 with a negative binomial distribution. The model had fish abundance as the response variable, 147 while the period before and after the perturbation was fitted as a predictor with data collection 148 site as a covariate. The model had the following structure: fish abundance $\sim$ period of data 149 collection + site. The model assumptions were checked with visual plots with the function 150 influencePlot () in R language.

151 
152 The second model tested for potential changes in the abundance within the eleven trophic-

153 functional groups. Here, we fitted a zero-inflated negative binomial distribution due to the

154 presence of many zeros in the count data. The zeros refer to the absence of some functional

155 groups in the transects. The site identity was fitted as a covariate to control for potential

156 differences between the two sites (R. Slobodeanu, personal communication). The model had the

157 following function: fish abundance $\sim$ functional group $*$ period of data collection + site. As post

158 hoc analyses for the second model, we ran least-squares means analyses with the function

159 emmeans () from the package (emmeans in R language). The emmeans () function uses the

160 Tukey method by default for multiple comparisons. The reported pseudo R-squared in the results

161 are the Nagelkerke (Cragg and Uhler) values generated with the nagelkerke() from the

162 package (rcompanion in R language) (see Liu, Zheng \& Shen, 2008). For further details about

163 statistical tests, R packages and script, please refer to our statistical script in the Figshare

164 repository (DOI: 10.6084/m9.figshare.4990919).

165

166 Ethical note:

167 The Animal Ethics Committee of the Queensland government (DAFF) approved the project (CA 168 2016/05/970 and CA 2017/05/1063).

169

170 Results:

171 Fish census data showed that total fish abundance significantly declined after the environmental

172 disturbances (ANOVA: $N=60$, estimate $=-1.239, X^{2}=52.885, p<0.001$, pseudo R-squared $=$

173 0.49, Figure 2), despite differences between the two study sites (ANOVA: $N=60$, estimate $=$ $\left.1740.519, X^{2}=9.583, p=0.002\right)$. On the other hand, fish functional groups provided more details 
175 on where the decline in fish density occurred, with a significant interaction of the trophic-

176 functional group and the period of data collection (ANOVA: $N=660, X^{2}=68.899$, pseudo R-

177 squared $=0.66, p<0.001$, Figure 3). Post hoc tests showed that ten out of the eleven functional

178 groups went through a significant change in fish abundance after the disturbances, of which nine

179 showed a decline (the contrast before - after): browsers (estimate $=1.534, z=3.427, p<0.001)$;

180 corallivores $($ estimate $=2.099, z=2.418, p=0.015)$; detrivores $($ estimate $=15.784, z=3.610, p$

$181<0.001)$; excavator/scrapers (estimate $=8.904, z=4.308, p<0.001)$; grazers $($ estimate $=11.836, z$

$182=2.617, p=0.009)$; macro-invertivores (estimate $=3.580, z=2.195, p=0.030)$; pisci-

183 invertivores (estimate $=1.133, z=2.337, p=0.020)$; planktivores (estimate $=102.06, z=4.340, p$

$184<0.001$ ); and spongivores (estimate $=39.951, z=3.479, p<0.001)$. Only piscivores showed a 185 significant increase in abundance (estimate $=-0.662, z=-2.277, p=0.022$ ), while micro186 invertivores were the only functional group that did not show any significant changes (estimate= $1876.956, z=1.152, p=0.249)$.

189 Discussion:

190

191 We identified a substantial decline in the density of reef fishes at Lizard Island following a 192 sequence of severe tropical cyclones and coral bleaching. We documented a $68 \%$ decline in fish 193 densities; a percentage close to what Wilson et al. (2006) found in their meta-analysis of 17 194 independent studies on fish density after environmental disturbances, in which an average 195 decline of $62 \%$ was observed in fish density within three years after disturbances including 196 cyclones and coral bleaching. These findings are in line with previous studies suggesting that the 197 loss of coral cover would lead to a reduction in fish density (Jones et al., 2004; Russ \& Leahy, 
198 2017; Pratchett et al., 2018). It suggests that the recorded decline in the present study might be

199 due to the loss of coral cover. Cyclones usually destroy the reef structure, which would impede

200 corals from possible rapid recovery (Cheal et al., 2002). Also, coral recovery might be

201 compromised if the reef is repeatedly exposed to tropical cyclones over short-time intervals

202 (De'ath et al., 2012; Puotinen et al., 2016). In addition to damage from cyclones, bleaching can

203 reduce coral cover (DiazPulido \& McCook, 2002). Recently, Stuart-Smith et al. (2018)

204 documented a $51 \%$ coral cover loss at the GBR after the 2016 bleaching event. Subsequently, it

205 is expected that habitat loss would lead to a decline in fish abundance (Pratchett et al., 2011;

206 Brandl et al., 2016). We acknowledge an important caveat in the present study: we were unable

207 to incorporate information about the benthic habitat structure and benthic communities. This

208 information would provide more insight into the fluctuations in reef-dependent fish communities

209 (Goren \& Spanier, 1985; Holbrook, Schmitt \& Stephens, 1997; Russ \& McCook, 1999; Wismer,

210 Hoey \& Bellwood, 2009; Pizarro et al., 2017; Prazeres, Roberts \& Pandolfi, 2017; Renfro \&

211 Chadwick, 2017). Also, due to the absence of data on the benthos, the significant effect of "site"

212 in our model is virtually impossible to interpret (see Supplementary Fig. S1 and Fig. S2).

213 Nevertheless, the significant decline in fish densities recorded here can still inform us about the

214 effect of extreme weather events on fish assemblages (Wilson et al., 2006).

215

216

Assessing fish density according to their trophic-functional groups showed a substantial decline

217 in nine out of eleven functional groups. This suggests that most fish, regardless of their trophic

218 affiliation, were susceptible to the disturbances. Nevertheless, the piscivore group was the only

219 group to benefit from such disturbances. It is possible that due to the damage of reef structure

220 and the resulting destruction of shelters, piscivores (i.e., reef-associated predators) would gain 
221 easy access to prey, from which they could benefit and thereby increase their numbers. Also, it is

222 possible that bleached corals might no longer be suitable shelters for coral-dwelling species

223 (Coker, Pratchett \& Munday, 2009; Pratchett et al., 2011), nor appropriate camouflage

224 background for small-bodied prey. As a consequence, predators would easily recognise their

225 prey (Phillips et al., 2017), which would eventually change the assemblage structure of these

226 predatory fishes (Emslie, Cheal \& Logan, 2017). Nevertheless, such an increase might be

227 transient in time and eventually be followed by a decline due to decreased numbers of prey.

228 Also, the erosion of corals skeleton over time might result in a reduction of shelter and hunting

229 options for ambush predators (Kerry \& Bellwood, 2012).

230

231 Graham et al. (2011) predicted that micro-invertivores are one of the trophic-functional groups

232 most vulnerable and macro-invertivores the least vulnerable to climate disturbances. Here, the

233 micro-invertivores were the only group without apparent changes from pre- to post-disturbance.

234 A potential explanation for this divergence is that micro-invertivores may show high functional

235 redundancy, where losses in particular species can be replaced by population increases in other

236 species that share a similar function (Micheli \& Halpern, 2005; Brandl et al., 2016).

237 Furthermore, we note that the decline in browsers, corallivores and pisci-invertivores, as well as

238 the increase in piscivores documented in this study, differ from previous results also collected

239 around Lizard Island (Ceccarelli, Emslie \& Richards, 2016; Brandl et al., 2016). One potential

240 explanation is that those previous studies used post-disturbance data collected in early 2015, i.e.

241 only a few months after hurricane Ita hit the island, while we collected data 2-3 years after

242 another cyclone and the El Niño event took place. A potential additional factor could be that the 
243 previous studies collected data in $3 \mathrm{~m}$ and $9 \mathrm{~m}$ depth, while our data include shallow areas of 1-

$2442 \mathrm{~m}$ depth.

245

246 The trophic-functional groups that were most abundant pre-disturbance, the planktivores and 247 spongivores, also showed a decline in numbers post-disturbances (Figure 3). For instance, 248 planktivores are mainly damselfish that are often highly coral-associated species (Feary et al., 249 2007; Wilson et al., 2008a), wherein habitat loss might explain the decline in their numbers. 250 Such losses can be detrimental to the ecosystem balance, mainly because the planktivores play 251 an important role in transferring nutrients from the pelagic environment onto the reef (Pace et al., 252 1999; Fisher et al., 2015). Spongivores also have a significant role in protecting corals by feeding 253 on overgrowing sponges, thereby reducing coral-sponge competition (Hill, 1998). The decrease 254 in fish density in the other functional groups: browsers, detritivores, grazers, and 255 excavators/scrapers, can also have severe consequences on the health and resilience of corals 256 after disturbances. These trophic-functional groups feed on macro-algae, which prevent the latter 257 from over-colonising the corals. Their functional role is hence beneficial for coral resilience, 258 coral settlement, and growth (Green \& Bellwood, 2009; Cheal et al., 2010; Rasher, Hoey \& Hay, 259 2013).

\section{Conclusion}

262

263 Environmental disturbances are expected to increase in frequency and magnitude due to global 264 warming. Here we found that such environmental events were followed by reductions in fish 265 densities across multiple trophic-functional groups around Lizard Island. These findings add to 
266 the data that shows that future coral reef fish communities are susceptible to significant changes

267 on this island. Supported by the larger scale fish assemblage changes across the GBR shown by 268 Hughes et al. (2018). It suggests that such losses can impact the functionality and stability of 269 these communities (Green \& Bellwood, 2009; Rasher, Honey \& Hay, 2013).

270

\section{Acknowledgement}

272 We kindly thank the staff of Lizard Island Research Station for their support and friendship, R.

273 Slobodeanu for his assistance with the statistical analyses, and J. McClung and Y. Emery for 274 their contribution with proofreading.

275 


\section{References:}

277 Bellwood DR, Hoey AS, Ackerman JL, Depczynski M. 2006. Coral bleaching, reef fish community

278

279

280

281

282

283

284

285

286

287

288

289

290

291

292

293

294

295

296

phase shifts and the resilience of coral reefs. Global Change Biology 12:1587-1594. DOI: 10.1111/j.1365-2486.2006.01204.x.

Bellwood DR, Hughes TP, Folke C, Nyström M. 2004. Confronting the coral reef crisis. Nature 429:827-833. DOI: 10.1038/nature02691.

Brandl SJ, Emslie MJ, Ceccarelli DM, T. Richards Z. 2016. Habitat degradation increases functional originality in highly diverse coral reef fish assemblages. Ecosphere 7:e01557. DOI: 10.1002/ecs2.1557.

Browman HI. 2016. Applying organized scepticism to ocean acidification research. ICES Journal of Marine Science: Journal du Conseil 73:529-536. DOI: 10.1093/icesjms/fsw010.

Butterfield BJ, Suding KN. 2013. Single-trait functional indices outperform multi-trait indices in linking environmental gradients and ecosystem services in a complex landscape. Journal of Ecology 101:9-17. DOI: 10.1111/1365-2745.12013.

Cai W, Borlace S, Lengaigne M, Rensch P van, Collins M, Vecchi G, Timmermann A, Santoso A, McPhaden MJ, Wu L, England MH, Wang G, Guilyardi E, Jin F-F. 2014. Increasing frequency of extreme El Nino events due to greenhouse warming. Nature Climate Change 4:111-116. DOI: 10.1038/nclimate2100.

Ceccarelli DM, Emslie MJ, Richards ZT. 2016. Post-Disturbance Stability of Fish Assemblages Measured at Coarse Taxonomic Resolution Masks Change at Finer Scales. PLOS ONE 11:e0156232. DOI: 10.1371/journal.pone.0156232. 
297 Cheal A, Coleman G, Delean S, Miller I, Osborne K, Sweatman H. 2002. Responses of coral and 298 fish assemblages to a severe but short-lived tropical cyclone on the Great Barrier Reef, $299 \quad$ Australia. Coral Reefs 21:131-142. DOI: 10.1007/s00338-002-0227-8.

300 Cheal AJ, MacNeil MA, Cripps E, Emslie MJ, Jonker M, Schaffelke B, Sweatman H. 2010. Coral301 macroalgal phase shifts or reef resilience: links with diversity and functional roles of 302 herbivorous fishes on the Great Barrier Reef. Coral Reefs 29:1005-1015. DOI:

303 10.1007/s00338-010-0661-y.

304 305 306

307 308 309 intense cyclones under climate change. Global Change Biology 23:1511-1524. DOI: 10.1111/gcb.13593.

Coker DJ, Pratchett MS, Munday PL. 2009. Coral bleaching and habitat degradation increase susceptibility to predation for coral-dwelling fishes. Behavioral Ecology 20:1204-1210. DOI: 10.1093/beheco/arp113.

De'ath G, Fabricius KE, Sweatman H, Puotinen M. 2012. The 27-year decline of coral cover on the Great Barrier Reef and its causes. Proceedings of the National Academy of Sciences 109:17995-17999. DOI: 10.1073/pnas.1208909109.

DiazPulido, McCook G. 2002. The fate of bleached corals: patterns and dynamics of algal recruitment. Marine Ecology Progress Series 232:115-128. DOI: 10.3354/meps232115.

Emslie MJ, Cheal AJ, Logan M. 2017. The distribution and abundance of reef-associated predatory fishes on the Great Barrier Reef. Coral Reefs:1-18. DOI: 10.1007/s00338-0171573-x. 
318 Feary DA, Almany GR, Jones GP, McCormick MI. 2007. Coral degradation and the structure of

319

320

321

322

323

324

325

326

327

328

329

330

331

332

333

334

335

336

337

338

339

tropical reef fish communities. Marine Ecology Progress Series 333:243-248. DOI:

10.3354/meps333243.

Ferrari MCO, Dixson DL, Munday PL, McCORMICK MI, Meekan MG, Sih A, Chivers DP. 2011.

Intrageneric variation in antipredator responses of coral reef fishes affected by ocean

acidification: implications for climate change projections on marine communities. Global Change Biology 17:2980-2986. DOI: 10.1111/j.1365-2486.2011.02439.x.

Fisher J a. D, Casini M, Frank KT, Möllmann C, Leggett WC, Daskalov G. 2015. The importance of within-system spatial variation in drivers of marine ecosystem regime shifts.

Philosophical Transactions of the Royal Society of London B: Biological Sciences 370:20130271. DOI: 10.1098/rstb.2013.0271.

Froese R, Pauly D. 2016. Editors. 2016. FishBase.World Wide Web electronic publication. www.fishbase.org, version (06/2016).

Ganasan V, Hughes RM. 1998. Application of an index of biological integrity (IBI) to fish assemblages of the rivers Khan and Kshipra (Madhya Pradesh), India. Freshwater Biology 40:367-383. DOI: 10.1046/j.1365-2427.1998.00347.x.

Goren M, Spanier E. 1985. The communities of benthic fish in foul bay (tiran island, red-sea). Oceanologica acta 8:471-478.

Graham NAJ, Chabanet P, Evans RD, Jennings S, Letourneur $Y$, Aaron MacNeil M, McClanahan TR, Öhman MC, Polunin NVC, Wilson SK. 2011. Extinction vulnerability of coral reef fishes: Reef fish extinction vulnerability. Ecology Letters 14:341-348. DOI:

10.1111/j.1461-0248.2011.01592.x. 
340 Graham NAJ, Jennings S, MacNeil MA, Mouillot D, Wilson SK. 2015. Predicting climate-driven

341 regime shifts versus rebound potential in coral reefs. Nature 518:94-97. DOI:

342 10.1038/nature14140.

343 Green AL, Bellwood DR. 2009. Monitoring functional groups of herbivorous reef fishes as 344 indicators of coral reef resilience: a practical guide for coral reef managers in the Asia Pacific region.

346

347

348

350

351

352

353

354

355

356

357

358

359

360

361

Hill MS. 1998. Spongivory on Caribbean reefs releases corals from competition with sponges. Oecologia 117:143-150. DOI: 10.1007/s004420050642.

Hoegh-Guldberg O, Ridgway T. 2016. Coral bleaching hits great barrier reef as global temperatures soar. Green Left Weekly:10.

Holbrook SJ, Schmitt RJ, Stephens JS. 1997. Changes in an Assemblage of Temperate Reef Fishes Associated with a Climate Shift. Ecological Applications 7:1299-1310. DOI: 10.1890/1051-0761(1997)007[1299:CIAAOT]2.0.CO;2.

Hughes TP, Anderson KD, Connolly SR, Heron SF, Kerry JT, Lough JM, Baird AH, Baum JK, Berumen ML, Bridge TC, Claar DC, Eakin CM, Gilmour JP, Graham NAJ, Harrison H, Hobbs J-PA, Hoey AS, Hoogenboom M, Lowe RJ, McCulloch MT, Pandolfi JM, Pratchett M, Schoepf V, Torda G, Wilson SK. 2018. Spatial and temporal patterns of mass bleaching of corals in the Anthropocene. Science 359:80-83. DOI: 10.1126/science.aan8048.

Hughes TP, Kerry JT, Álvarez-Noriega M, Álvarez-Romero JG, Anderson KD, Baird AH, Babcock RC, Beger M, Bellwood DR, Berkelmans R, Bridge TC, Butler IR, Byrne M, Cantin NE, Comeau S, Connolly SR, Cumming GS, Dalton SJ, Diaz-Pulido G, Eakin CM, Figueira WF, Gilmour JP, Harrison HB, Heron SF, Hoey AS, Hobbs J-PA, Hoogenboom MO, Kennedy 
EV, Kuo C, Lough JM, Lowe RJ, Liu G, McCulloch MT, Malcolm HA, McWilliam MJ, Pandolfi JM, Pears RJ, Pratchett MS, Schoepf V, Simpson T, Skirving WJ, Sommer B, Torda G, Wachenfeld DR, Willis BL, Wilson SK. 2017. Global warming and recurrent mass bleaching of corals. Nature 543:373-377. DOI: 10.1038/nature21707.

366

367

368

369

370

371

372

373

374

375

376

377

378

379

380

381

382

Jones GP, McCormick MI, Srinivasan M, Eagle JV. 2004. Coral decline threatens fish biodiversity in marine reserves. Proceedings of the National Academy of Sciences 101:8251-8253. DOI: $10.1073 / p n a s .0401277101$.

Karr JR. 1981. Assessment of Biotic Integrity Using Fish Communities. Fisheries 6:21-27. DOI: 10.1577/1548-8446(1981)006<0021:AOBIUF>2.0.CO;2.

Kerry JT, Bellwood DR. 2012. The effect of coral morphology on shelter selection by coral reef fishes. Coral Reefs 31:415-424. DOI: 10.1007/s00338-011-0859-7.

Liu H, Zheng Y, Shen J. 2008. Goodness-of-fit measures of $R^{2}$ for repeated measures mixed effect models. Journal of Applied Statistics 35:1081-1092. DOI: $10.1080 / 02664760802124422$.

MacNeil MA, Graham NAJ, Cinner JE, Wilson SK, Williams ID, Maina J, Newman S, Friedlander AM, Jupiter S, Polunin NVC, McClanahan TR. 2015. Recovery potential of the world's coral reef fishes. Nature 520:341-344. DOI: 10.1038/nature14358.

Micheli F, Halpern BS. 2005. Low functional redundancy in coastal marine assemblages. Ecology Letters 8:391-400. DOI: 10.1111/j.1461-0248.2005.00731.x.

Munday PL. 2004. Habitat loss, resource specialization, and extinction on coral reefs. Global Change Biology 10:1642-1647. DOI: 10.1111/j.1365-2486.2004.00839.x. 
383 Munday PL, Jones GP, Pratchett MS, Williams AJ. 2008. Climate change and the future for coral 384 reef fishes. Fish and Fisheries 9:261-285. DOI: 10.1111/j.1467-2979.2008.00281.x. 385
Pace ML, Cole JJ, Carpenter SR, Kitchell JF. 1999. Trophic cascades revealed in diverse ecosystems. Trends in Ecology \& Evolution 14:483-488. DOI: 10.1016/S01695347(99)01723-1.

Phillips GAC, How MJ, Lange JE, Marshall NJ, Cheney KL. 2017. Disruptive colouration in reef fish: does matching the background reduce predation risk? Journal of Experimental Biology 220:1962-1974. DOI: 10.1242/jeb.151480.

Pizarro O, Friedman A, Bryson M, Williams SB, Madin J. 2017. A simple, fast, and repeatable survey method for underwater visual 3D benthic mapping and monitoring. Ecology and Evolution 7:1770-1782. DOI: 10.1002/ece3.2701.

Pratchett MS, Hoey AS, Wilson SK, Messmer V, Graham NAJ. 2011. Changes in Biodiversity and Functioning of Reef Fish Assemblages following Coral Bleaching and Coral Loss. Diversity 3:424-452. DOI: 10.3390/d3030424.

Pratchett MS, Munday P, Wilson SK, Graham NA, Cinner JE, Bellwood DR, Jones GP, Polunin NV, McClanahan TR. 2008. Effects of climate-induced coral bleaching on coral-reef fishes. Ecological and economic consequences. Oceanography and Marine Biology: Annual Review 46:251-296.

Pratchett MS, Thompson CA, Hoey AS, Cowman PF, Wilson SK. 2018. Effects of Coral Bleaching and Coral Loss on the Structure and Function of Reef Fish Assemblages. In: Coral Bleaching. Ecological Studies. Springer, Cham, 265-293. DOI: 10.1007/978-3-319-753935_11. 
405 Prazeres M, Roberts TE, Pandolfi JM. 2017. Shifts in species abundance of large benthic 406 foraminifera Amphistegina: the possible effects of Tropical Cyclone Ita. Coral Reefs 407 36:305-309. DOI: 10.1007/s00338-016-1497-x.

408

409

410

411

412

413

414

415

416

417

418

419

420

421

422

423

424

425

Puotinen M, Maynard JA, Beeden R, Radford B, Williams GJ. 2016. A robust operational model for predicting where tropical cyclone waves damage coral reefs. Scientific Reports 6. DOI: 10.1038/srep26009.

Randall JE. 1961. Overgrazing of Algae by Herbivorous Marine Fishes. Ecology 42:812-812. DOI: $10.2307 / 1933510$.

Rasher DB, Hoey AS, Hay ME. 2013. Consumer diversity interacts with prey defenses to drive ecosystem function. Ecology 94:1347-1358. DOI: 10.1890/12-0389.1.

Renfro B, Chadwick NE. 2017. Benthic community structure on coral reefs exposed to intensive recreational snorkeling. PLOS ONE 12:e0184175. DOI: 10.1371/journal.pone.0184175.

Russ GR, Leahy SM. 2017. Rapid decline and decadal-scale recovery of corals and <Emphasis Type="Italic">Chaetodon</Emphasis $>$ butterflyfish on Philippine coral reefs. Marine Biology 164:29. DOI: 10.1007/s00227-016-3056-y.

Russ GR, McCook L. 1999. Potential effects of a cyclone on benthic algal production and yield to grazers on coral reefs across the central Great Barrier Reef. Journal of Experimental Marine Biology and Ecology 235:237-254. DOI: 10.1016/S0022-0981(98)00180-4.

Stuart-Smith RD, Brown CJ, Ceccarelli DM, Edgar GJ. 2018. Ecosystem restructuring along the Great Barrier Reef following mass coral bleaching. Nature 560:92-96. DOI: 10.1038/s41586-018-0359-9. 
426 Triki Z, Wismer S, Levorato E, Bshary R. 2018. A decrease in the abundance and strategic

427

428

429

430

431

432

433

434

435

436

437

438

439

440

441

442

443

444

445 sophistication of cleaner fish after environmental perturbations. Global Change Biology 24:481-489. DOI: 10.1111/gcb.13943.

Wernberg T, Smale DA, Tuya F, Thomsen MS, Langlois TJ, de Bettignies T, Bennett S, Rousseaux CS. 2013. An extreme climatic event alters marine ecosystem structure in a global biodiversity hotspot. Nature Climate Change 3:78-82. DOI: 10.1038/nclimate1627.

Wilson SK, Burgess SC, Cheal AJ, Emslie M, Fisher R, Miller I, Polunin NVC, Sweatman HPA. 2008a. Habitat utilization by coral reef fish: implications for specialists vs. generalists in a changing environment. Journal of Animal Ecology 77:220-228. DOI: 10.1111/j.13652656.2007.01341.x.

Wilson SK, Fisher R, Pratchett MS, Graham N a. J, Dulvy NK, Turner RA, Cakacaka A, Polunin NVC. 2010. Habitat degradation and fishing effects on the size structure of coral reef fish communities. Ecological Applications 20:442-451. DOI: 10.1890/08-2205.1.

Wilson SK, Fisher R, Pratchett MS, Graham N a. J, Dulvy NK, Turner RA, Cakacaka A, Polunin NVC, Rushton SP. 2008b. Exploitation and habitat degradation as agents of change within coral reef fish communities. Global Change Biology 14:2796-2809. DOI: 10.1111/j.1365-2486.2008.01696.x.

Wilson SK, Graham N a. J, Pratchett MS, Jones GP, Polunin NVC. 2006. Multiple disturbances and the global degradation of coral reefs: are reef fishes at risk or resilient? Global Change Biology 12:2220-2234. DOI: 10.1111/j.1365-2486.2006.01252.x. 
446 Wismer S, Hoey A, Bellwood DR. 2009. Cross-shelf benthic community structure on the Great 447 Barrier Reef: relationships between macroalgal cover and herbivore biomass. Marine $448 \quad$ Ecology Progress Series 376:45-54.

449 Wismer S, Pinto Al, Vail AL, Grutter AS, Bshary R. 2014. Variation in Cleaner Wrasse Cooperation 450 and Cognition: Influence of the Developmental Environment? Ethology 120:519-531.

$451 \quad$ DOI: 10.1111/eth.12223.

452 


\section{Figure 1 (on next page)}

Lizard Island group map.

The map is showing the two study sites: Mermaid Cove reef as Site 1 and Northern horseshoe reef as Site2. Modified from Triki et al. 2018, Global Change Biology (๔ 2017 John Wiley \& Sons Ltd). 


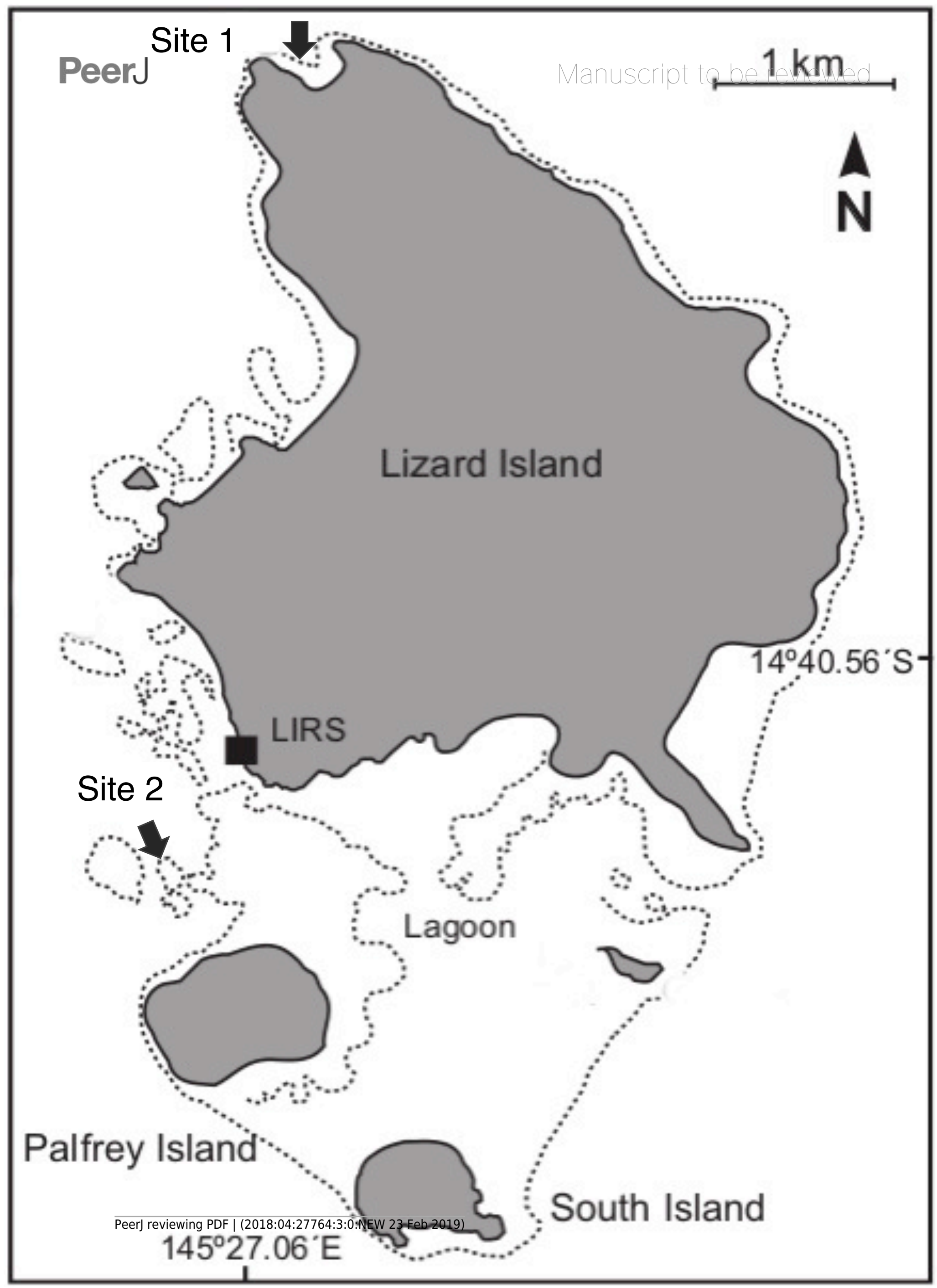




\section{Figure 2 (on next page)}

Total fish abundance.

Boxplots are displaying median and interquartile of total fish abundance before $(n=20)$ and after $(n=40)$ the environmental disturbances (i.e., cyclones and coral bleaching). Negative binomial Generalised Linear Model: *** $p<0.001$. 


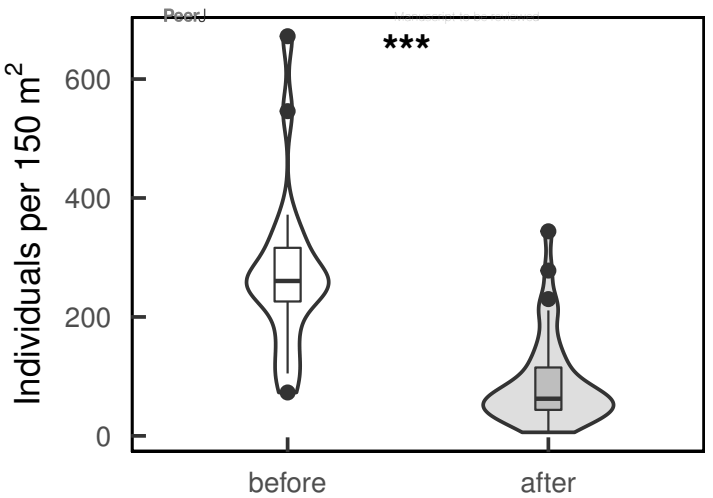


Figure 3 (on next page)

Fish abundance per trophic-functional groups

Boxplots are displaying median and interquartile of fish abundance within trophic-functional groups showing eventual changes from before $(n=20)$ to after $(n=40)$ the environmental disturbances (i.e., cyclones and coral bleaching). Note that due to the high variation in fish counts per functional group, the $y$-axes do not have the same scale. Post hoc analyses of a Zero-inflated negative binomial model showing differences between before and after the perturbations within each functional group: * $p<0.05$; ** $p<0.01 ; * * * p<0.001$. 


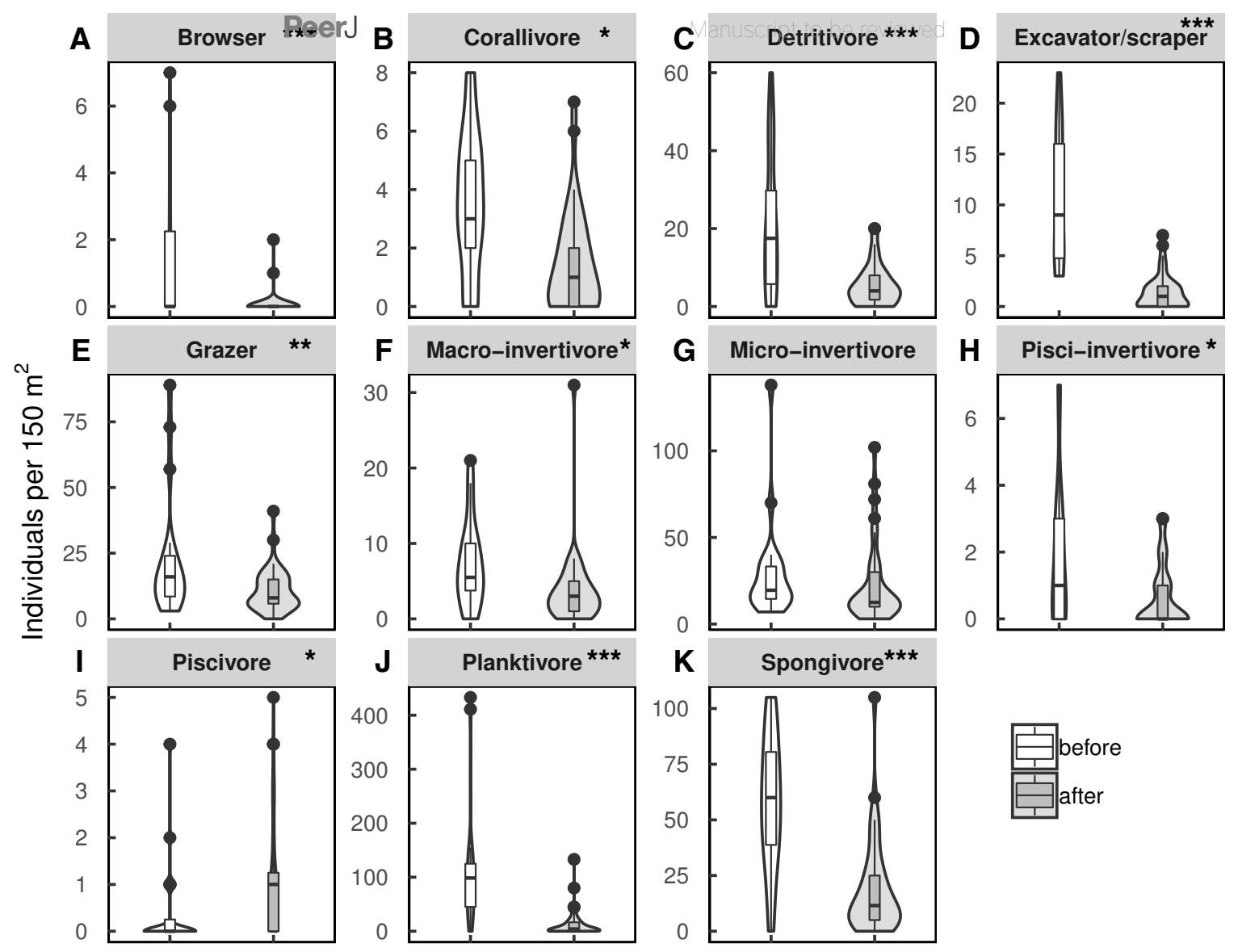




\section{Table $\mathbf{1}$ (on next page)}

Dietary functional trait used in sorting fish species into trophic-functional groups. 


\begin{tabular}{|l|l|l|}
\hline Trophic-functional group & Diet & Example \\
\hline Browsers & Macro-algae & Naso unicornis \\
\hline Corallivores & Corals & Chaetodon aureofasciatus \\
\hline Detritivores & $\begin{array}{l}\text { Dead organic material } \\
\text { "detritus" }\end{array}$ & Ctenochaetus striatus \\
\hline Excavators/scrapers & $\begin{array}{l}\text { Remove reef substrate while } \\
\text { looking for living material }\end{array}$ & Chlorurus spilurus \\
\hline Grazers & $\begin{array}{l}\text { Fast-growing macro-algae } \\
\text { "turf algae" }\end{array}$ & Siganus doliatus \\
\hline Macro-invertivores & Large invertebrates & Balistapus undulatus \\
\hline Micro-invertivores & Small invertebrates & Coris batuensis \\
\hline Pisci-invertivores & Fish and invertebrates & Lethrinus olivaceus \\
\hline Piscivores & Fish & Epinephelus merra \\
\hline Planktivores & Plankton & Abudefduf sexfasciatus \\
\hline Spongivores & Sea sponges & Pomacanthus sexstriatus \\
\hline
\end{tabular}

